\title{
Ceramic-Supported Polyhedral Oligomeric Silsesquioxane-Organosilica Nanocomposite Membrane for Efficient Gas Separation
}

Xiuxiu Ren, ${ }^{* \dagger}$ Masakoto Kanezashi, ${ }^{*}$ Hiroki Nagasawa, ${ }^{+}$Rong Xu, ${ }^{\dagger}$ Jing Zhong, ${ }^{\dagger}$ and Toshinori Tsuru*t.

†Jiangsu Key Laboratory of Advanced Catalytic Materials and Technology, School of Petrochemical Engineering, Changzhou University, Changzhou, 213164, China.

* Separation Engineering Laboratory, Department of Chemical Engineering, Hiroshima University, 1-4-1, Kagamiyama, Higashi-Hiroshima, 739-8527, Japan.

------ (SI-1) ------

The diffusivity $(D)$ of $\mathrm{CO}_{2}$ as a function of POSS content is shown in Figure $\mathrm{S} 1 . D$ is calculated based on the equation: $P=D \cdot S . P$ is the permeability that can be calculated using the permeance of $\mathrm{CO}_{2}\left(40^{\circ} \mathrm{C}\right)$ divided by the membrane thickness of $200 \mathrm{~nm} .{ }^{23,25}$ The solubility of $S$ is obtained from the adsorption amount of $\mathrm{CO}_{2}$ at $308 \mathrm{~K}$ (pure BTESE was tested at $298 \mathrm{~K}$ ). 


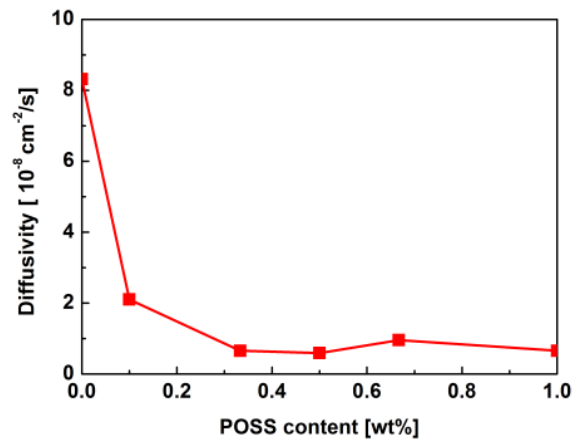

Figure S1. Diffusivity of $\mathrm{CO}_{2}$ around $40{ }^{\circ} \mathrm{C}$ as a function of POSS content.<smiles>C=[AsH2]</smiles>

The surface morphology of BTESE-POSS composite film was characterized via a laser microscope (KEYENCE, VK-X200), as shown in Figure S2.

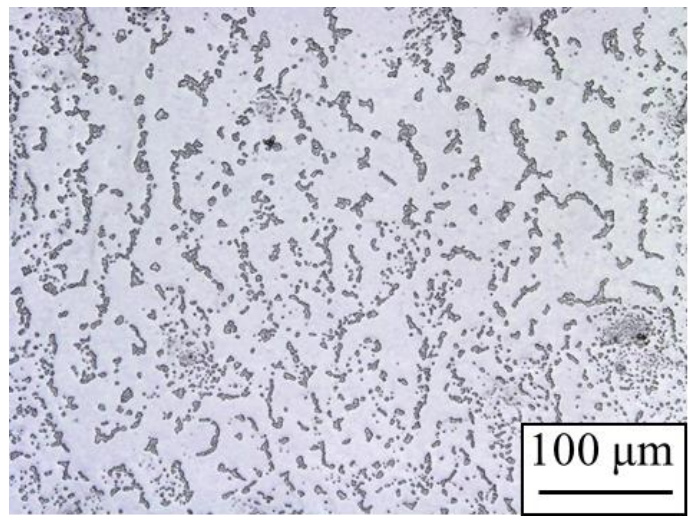

Figure S2. Microscopic surface image of BTESE-POSS (33.3\%) film. 